0,028 ), as well as with the presence of erosions, GF, HTA and dyslipidemia. The appearance of cardiac events was related, also, with the use of NSAID $(p 0,041)$. The presence of a pathologic IMT $(p 0,032)$ and HTA $(p 0,044)$ were the only variables related with death from any cause.

Conclusions: A combination of carotid ultrasonography and arterial stiffness study can help us to best identify patients with RA who have an increased risk of dying or developing a vascular event.

Disclosure of Interest: None declared

DOI: 10.1136/annrheumdis-2017-eular.3469

\section{THU0154 ASSOCIATION BETWEEN PLASMA LIPIDS, DISEASE ACTIVITY AND PCSK9 LEVELS IN RA PATIENTS}

M. Heslinga ${ }^{1}$, G. Lambert ${ }^{2}$, A. Thedrez ${ }^{3}$, J. Kastelein ${ }^{4}$, M. Nurmohamed ${ }^{1,5}$. ${ }^{1}$ Amsterdam Rheumatology and immunology Center / Reade, Amsterdam, Netherlands; ${ }^{2}$ University of la Reúnion, Saint-Denis; ${ }^{3}$ University of Nantes, Nantes, France; ${ }^{4}$ Academic Medical Center $;{ }^{5}$ Amsterdam Rheumatology and Immunology Center / VU University Medical Center, Amsterdam, Netherlands

Background: Patients with rheumatoid arthritis (RA) are at increased cardiovascular risk with contribution of both inflammation and traditional risk factors. Dyslipidemia is an important risk factor and lipid-lowering therapy plays a key role in cardio-preventive treatment. A new class of low density lipoprotein cholesterol (LDL-C) lowering drugs, proprotein convertase subtilisin/kexin type 9 (PCSK9)inhibitors are now emerging. In view of a lower rate of musculoskeletal side effects these drugs might be preferred over statins in patients with RA. Active inflammation in RA leads to a decline in lipid levels, but the relation between inflammation and PCSK9 levels is unknown.

Objectives: To assess PSCK9 levels in RA patients, and the relationship with lipid levels and disease activity.

Methods: PSCK9 levels were assessed using ELISA in 97 randomly selected patients. Lipid profile assessment comprised TC, HDL-C, LDL-C and triglycerides. Disease activity was assessed using disease activity score of 28 joints (DAS28). Results: The mean age of RA patients was 54.5 years $( \pm 10.8)$ and they were predominantly female $(74.2 \%)$. The mean PCSK9 value in RA patients was 214.75 ( \pm 73.3), which is similar to that in the general population [1]. PCSK9 values were associated with TC (corrected B $22.34,95 \% \mathrm{Cl} 6.80-37.88, \mathrm{p} 0.005$ ) and triglycerides (corrected B 21.02, 95\% Cl -0.84-42.89, p0.044) (table 2). 77 patients had low disease activity (DAS28 $\leq 3.2$ ), 11 patients had medium disease activity (DAS28 $>3.2$ and $\leq 5.1$ ) and 20 patients had highly active disease (DAS28 >5.1). Mean PCSK9 values were $213.01,246.96$ and $258.30 \mathrm{ng} / \mathrm{mL}$, respectively. Patients with active disease had a higher PCSK9 level (corrected B $42.55595 \%$ $\mathrm{Cl}$ 0.769-84.341, p 0.046) compared to patients with low disease activity (table 1).

Table 1. Relation between plasma lipids, disease activity and PCSK9 levels

\begin{tabular}{|c|c|c|c|}
\hline & B & $95 \% \mathrm{Cl}$ & P-value \\
\hline TC & 21.86 & $7.03-36.69$ & 0.004 \\
\hline & 21.88 & $6.52-37.24$ & 0.006 \\
\hline ** & 22.34 & $6.80-37.88$ & 0.005 \\
\hline Triglycerides & 21.02 & $-0.84-42.89$ & 0.059 \\
\hline * & 19.81 & $-2.91-42.53$ & 0.087 \\
\hline ** & 24.81 & $0.68-48.94$ & 0.044 \\
\hline HDL-C & 13.03 & $-14.97-41.03$ & 0.358 \\
\hline & 14.57 & $-14.61-43.79$ & 0.324 \\
\hline ** & 11.04 & $-20.15-42.23$ & 0.484 \\
\hline LDL-C & 14.23 & $-1.93-30.38$ & 0.084 \\
\hline & 13.59 & $-2.81-29.99$ & 0.103 \\
\hline$\star \star$ & 15.22 & $-1.51-31.95$ & 0.074 \\
\hline TC/HDL ratio & 6.28 & $-4.4-16.9$ & 0.245 \\
\hline & 5.95 & $-5.12-17.03$ & 0.289 \\
\hline$\star \star$ & 8.64 & $-3.36-20.64$ & 0.156 \\
\hline DAS28 (low vs. high disease activity) ${ }^{\dagger}$ & 45.284 & $4.865-85.884$ & 0.029 \\
\hline & 42.028 & $0.652-83.405$ & 0.047 \\
\hline ** & 42.555 & $0.769-84.341$ & 0.046 \\
\hline
\end{tabular}

${ }^{*}$ Corrected for age and gender, ${ }^{* *}$ Corrected for age, gender and BMI. ${ }^{+}$Low disease activity: DAS28 > 3.2, and high disease activity: DAS28 <5.1. BMI = Body Mass Index, DAS28 = Disease activity score of 28 joints, $\mathrm{HDL}=$ high density lipoprotein, $\mathrm{LDL}=$ low density lipoprotein, $\mathrm{TC}=$ Total cholesterol.

Conclusions: PCSK9 levels in RA are similar to the general population. RA patients with active disease had higher PCSK9 levels compared to patients with low disease activity. Altogether, PCSK9 inhibitors could be an alternative treatment for dyslipidemia in RA patients who experience side effects of statins, albeit that a formal trial still has to be conducted in this category of patients.

References:

[1] Lambert G, Petrides F, Chatelais M et al. J Am Coll Cardiol. 2014 Jun 10;63(22):2365-73.

Disclosure of Interest: None declared

DOI: 10.1136/annrheumdis-2017-eular.2121

\section{THU0155 IMPACT OF BASELINE MODIFIED RHEUMATIC DISEASE COMORBIDITY INDEX (MRDCI) ON DRUG SURVIVAL AND EFFECTIVENESS OF BIOLOGICAL DRUGS IN PATIENTS AFFECTED WITH RHEUMATOID ARTHRITIS (RA), SPONDYLOARTHRITIS (SPA), AND PSORIATIC ARTHRITIS (PSA) IN REAL-WORLD SETTINGS}

M. Fornaro ${ }^{1}$, M. Di Carlo ${ }^{2}$, S. Gentileschi ${ }^{3}$, M.G. Giannotta ${ }^{1}$, L. Cantarini ${ }^{3}$, F. Salaffi ${ }^{2}$, G. Lapadula ${ }^{1}$, F. lannone ${ }^{1} .{ }^{1}$ Department of Rheumatology, University of Bari, Bari; ${ }^{2}$ Rheumatology Department, Polytechnic University of Marche, Jesi; ${ }^{3}$ Research Center of Systemic Autoinflammatory Diseases and Behçet's Disease Clinic, Department of Medical Sciences, Surgery and Neurosciences, University of Siena, Siena, Italy

Background: The overall assessment of patients with systemic arthritis can not exclude comorbidities, which may impact therapeutic outcomes.

Objectives: To assess the impact of baseline modified rheumatic disease comorbidity index ${ }^{1}(\mathrm{mRDCl})$ on drug survival and effectiveness of biological drugs in patients affected with Rheumatoid arthritis (RA), Spondyloarthritis (SpA), and Psoriatic Arthritis (PsA) in real-world settings.

Methods: Patients (nr. 635) with RA (nr. 214), SpA (nr. 213), and PsA (nr. 208) starting a biological drug were retrospectively analysed. $\mathrm{mRDCl}$ was scored at baseline, and disease characteristics were recorded at entry and at last observation. Drug retention was analysed using Kaplan-Meier curves. Cox-regression models were used to estimate the association of $\mathrm{mRDCl}$ with drug discontinuation and clinical outcomes, the achievement of clinical remission based on 28 joint-Disease Activity Score (DAS28) $<2.6$ for RA and PsA, and on Ankylosing Spondylitis-C-reactive protein Disease Activity Score (ASDAS-CRP) $<1.3$ for SpA.

Results: Baseline $\mathrm{mRDCl}$ significantly correlated with the number of biological drug switches (rho 0.47). Drug persistence was significantly higher in patients with $\mathrm{mRDCl}=0(96.4 \%)$, than in those with $\mathrm{mRDCl} \geq 2(83.9 \%)$. Compared to $\mathrm{mRDCl} \geq 2$ patients, those without comorbidities showed significantly higher drug survival rate in $\mathrm{PsA}(\mathrm{p}=0.0001)$ or $\mathrm{SpA}(\mathrm{p}=0.02)$, but not in RA (Figure 1). $\mathrm{mRDCl}$ was also found to be a predictor of definitive drug discontinuation (HR 1.53) and of failure to achieve DAS28 based remission in RA (HR 0.66) or PSA (HR 0.77), and ASDAS-CRP driven remission in SpA (HR 0.43).

Table 1. Baseline demographics of patients with Psoriatic Arthritis (PsA), Rheumatoid arthritis (RA), and Spondyloarthritis (SpA)

\begin{tabular}{lcccc}
\hline & All $(\mathrm{n}=635)$ & PsA $(\mathrm{n}=208)$ & $\mathrm{RA}(\mathrm{n}=214)$ & $\mathrm{SpA}(\mathrm{n}=213)$ \\
\hline Age (mean \pm SD) & $51.1 \pm 13$ & $51.3 \pm 12$ & $54.2 \pm 12$ & $47.8 \pm 13$ \\
Female, $\mathrm{n}(\%)$ & $407(64)$ & $136(65)$ & $172(80)$ & $99(46)$ \\
Normal weight (BMI $\leq 25), \mathrm{n}(\%)$ & $278(44)$ & $84(40)$ & $111(52)$ & $83(39)$ \\
Overweight (BMI > 25 $\leq 30), \mathrm{n}(\%)$ & $242(28)$ & $78(37)$ & $64(30)$ & $100(47)$ \\
Obese (BMI >30), $\mathrm{n}(\%)$ & $115(18)$ & $46(22)$ & $39(18)$ & $30(14)$ \\
Disease duration (months) & $79.8 \pm 92$ & $69.9 \pm 123$ & $72.8 \pm 75$ & $74.9 \pm 80$ \\
mRDCl, $\mathrm{n}(\%)$ & & & & \\
0 & $302(48)$ & $87(42)$ & $92(43)$ & $123(58)$ \\
1 & $128(21)$ & $51(25)$ & $44(21)$ & $33(15)$ \\
2 & $88(14)$ & $24(12)$ & $34(16)$ & $30(14)$ \\
3 & $53(8.3)$ & $24(11)$ & $15(7.0)$ & $14(6.6)$ \\
4 & $30(4.7)$ & $12(5.8)$ & $12(5.6)$ & $6(2.8)$ \\
5 & $13(2.0)$ & $5(2.4)$ & $7(3.3)$ & $1(0.5)$ \\
6 & $9(1.4)$ & $2(1.0)$ & $6(2.8)$ & $1(0.5)$ \\
7 & $9(1.4)$ & $2(1.0)$ & $3(1.4)$ & $4(1.9)$ \\
8 & $3(0.5)$ & $1(0.5)$ & $1(0.5)$ & $1(0.5)$ \\
\hline
\end{tabular}

Values are the mean $1 \mathrm{SD}$ unless otherwise indicated. $\mathrm{BMI}=$ Body Mass Index; $\mathrm{mRDCl}=$ modified Rheumatic Diseases Comorbidity Index.
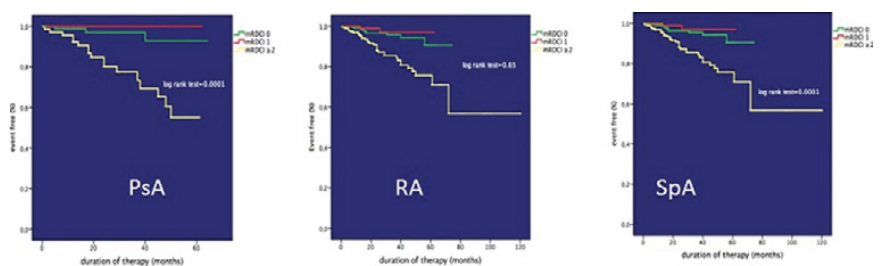

Figure 1. Kaplan-Meier
Psoriatic Arthritis $(\mathrm{P} B \mathrm{~A})$

Conclusions: This study provided evidence that baseline $\mathrm{mRDCl}$ negatively impacts the persistence on biologic treatments and the clinical outcomes in patients with RA, SpA, and PsA in real-life settings.

References:

[1] Staetgens et al. Content and construct validity of the Rheumatic Diseases Comorbidity Index in patients with gout. Rheumatology (2015)Sep;54(9):16591663.

Disclosure of Interest: None declared

DOI: 10.1136/annrheumdis-2017-eular.1502 